\title{
Soweto, 1976: Die Südafrika-Politik der DDR
}

Als Mitte der 1970er Jahre im ärmlichen und nur von schwarzen Afrikanern bewohnten Vorort Soweto der südafrikanischen Metropole Johannesburg die Polizei eine spontane Demonstration von schwarzen Schülern blutig auseinanderknüppelte und Dutzende junger Menschen niederschoss, schreckte die Welt, die sich nach den KSZE-Verhandlungen in einem begrenzten Prozess der Entspannung befand', auf. Mit einmal stand die menschenverachtende Apartheid der Republik Südafrika (RSA) wieder im Mittelpunkt der weltweiten kritischen Öffentlichkeit: Der Polizeieinsatz kostete etwa 600 Menschen das Leben, davon waren ein Viertel Kinder. Es gab wohl kaum eine Stimme, die nicht das Massaker im Land am Kap verurteilte. Ein wahrer Proteststurm breitete sich von Nord bis Süd, von Ost bis West über den Erdball aus.

Die östliche Seite in der damals bipolaren Welt nutzte den die Menschenrechte aufs Gröbste verletzenden Akt nicht nur, um die staatlich sanktionierte Mordtat an sich zu verurteilen, sondern auch, um ausländische Unterstützer und Profiteure des Apartheidregimes anzuklagen. So projizierte die DDR etwa den deutsch-deutschen Gegensatz in die Verurteilung der Menschenrechtsverletzungen im Süden Afrikas hinein. „Die DDR kann nicht umhin, darauf hinzuweisen, dass diejenigen, die ihre Zusammenarbeit mit diesem Regime selbst angesichts der jüngsten Ereignisse fortsetzen, zur weiteren Aufrechterhaltung der Herrschaft des Apartheidstaates beitragen und den afrikanischen Völkern in ihrem gerechten Kampf in den Rücken fallen“, hieß es beispielsweise in einer offiziellen Erklärung des Außenministeriums der DDR. ${ }^{2}$ Wenn auch propagandistisch überzeichnet, konnte sich die Erklärung doch auf Fakten stützen. Diverse Banken und Großkonzerne insbesondere aus Westeuropa - und darunter vor allem aus der Bundesrepublik und der Schweiz ${ }^{3}$ - profitierten von der Apartheid ${ }^{4}$ und arbeiteten auf staatlicher Ebene, beispielsweise bei der Unterstützung der Sicherheitskräfte des Apartheidregimes ${ }^{5}$, wie auch auf privater Ebene eng mit offiziellen Stellen bzw. Wirtschaftsunternehmen der Republik Süd-

1 Vgl. Yvan Vanden Berghe, Der Kalte Krieg 1917-1991, Leipzig 2002, S. 271.

2 Aus der Erklärung des Außenministers der DDR im Namen des Ministerrates, zitiert in: Klaus Brade, Südafrika - Apartheid - Befreiungskampf, Berlin 1978, S.6.

${ }^{3}$ Vgl. Mascha Madörin/Gottfried Wellmer/Martina Egli, Apartheidschulden. Der Anteil Deutschlands und der Schweiz, Stuttgart 1999.

${ }^{4}$ Vgl. H. Koch, Bundesrepublik - Südafrika Handelspartner No. 1, in: Informationsdienst Südliches Afrika, Nr. 10/11 (1978), S. 11 ff.; Gottfried Wellmer, Verflechtungen bundesrepublikanischer transnationaler Konzerne mit Südafrika, in: Wolff Geisler/Gottfried Wellmer, DM-Investitionen in Südafrika, Bonn 1983, S. 7ff.; Stoppt die Verbündeten der Apartheid. Materialheft zur Südafrika-Aktionsdekade, hrsg. vom Bund der Deutschen Katholischen Jugend, Stuttgart 1989; Günter Verheugen, Apartheid. Südafrika und die deutschen Interessen am Kap, Köln 1986.

" Dagegen richteten sich vielfältige Aktionen der bundesdeutschen Anti-Apartheid-Bewegung. Vgl. u.a. Apartheid tötet - boykottiert Südafrika! Dokumentation der bremischen Südafrika-Wochen (12. -27. 12. 1979), hrsg. von der Anti-Apartheid-Bewegung e. V., Gruppe Bremen, Bremen 1980. 
afrika zusammen ${ }^{6}$, und sie ließen sich auch nicht von Protesten der Anti-Apartheid-Bewegung im eigenen Land eines Besseren belehren. ${ }^{7}$

Um sich nicht alleine den „Schwarzen Peter" zuschieben zu lassen, wurden von westlicher Seite vereinzelte Stimmen laut, die den Osten der geheimen Unterstützung des Apartheidregimes bezichtigten. Gerade für die Vorwürfe gegen die DDR, die insbesondere von westlichen Journalisten vorgebracht wurden, konnten indes keine substantiellen Belege beigebracht werden. ${ }^{8}$ Denn schon seit mehr als einem Jahrzehnt vor den Ereignissen von Soweto hatte die DDR ihre Handelskontakte zum Regime im Süden Afrikas trotz schmerzhafter Verluste in ihrer Außenhandelsbilanz abgebrochen. Wie war es dazu gekommen?

\section{Die DDR und der Boykott des Apartheidregimes}

In einem Brief vom Juli 1963 hatte die Führung der Sozialistischen Einheitspartei Deutschlands (SED) der Südafrikanischen Kommunistischen Partei (SACP) die Unterstützung des Volkes der DDR für die bei Rivonia festgenommenen ANC-Führer zugesichert ${ }^{9}$ und sie zugleich über ihre Absicht informiert, Sanktionen gegen den Apartheidstaat zu verhängen. Der Außenhandelsminister der DDR wies schon kurz darauf die ihm nachgeordneten Einrichtungen an, den Handel mit allen Institutionen Südafrikas einzustellen, bestehende Exportverträge auslaufen zu lassen, den Export von Jagdwaffen und der dazugehörigen Munition indes sofort zu beenden. ${ }^{11}$ Die DDR hatte zwar schon zuvor erklärt, dass sie den Kampf gegen Rassismus auf dem afrikanischen Kontinent mit allen ihr zu Gebote stehenden Mitteln unterstützen wolle. Sie war indes bislang vor ökonomischen Sanktionen zurückgeschreckt, weil ihre eigene Wirtschaft darunter zu leiden gehabt hätte. Zu Beginn der 1960er Jahre, als die internationalen Proteste gegen die Apartheid immer stärker anschwollen, konnte sich die DDR dem vehement erhobenen Ruf nach internationalen Wirtschaftssanktionen aber nicht länger verschließen. Die DDR gehörte nach ihrem Selbstverständnis zusammen mit der Sowjetunion und den anderen sozialistischen Ländern zu denjenigen Staaten, die die Beschlüsse der UNO zur Ausmerzung der Rassendiskriminierung, zur Beseitigung jeglicher kolonialer Abhängigkeit und Unterdrückung und zur Sicherung

${ }^{6}$ Vgl. beispielsweise Nukleare Zusammenarbeit zwischen Bundesrepublik und Südafrika. Dokumentation des ANC of South Africa, in: 3. Welt Magazin, Nr.3/4 (1975); Dokumentation: Kongreß gegen atomare Zusammenarbeit Bundesrepublik - Südafrika, hrsg. von der Anti-Apartheid-Bewegung in der Bundesrepublik und Berlin (West), Bonn 1979.

7 Vgl. Jürgen Bacia/Dorothée Leidig, „Kauft keine Früchte aus Südafrika“. Geschichte der Anti-Apartheid-Bewegung, Frankfurt a. M. 2008.

${ }^{8}$ Vgl. Ulrich van der Heyden, Die DDR und der Handel mit dem Apartheidregime in Südafrika, Berlin 2004.

9 Vgl. Ilona Schleicher, Die Solidarität der DDR mit dem ANC; während des Rivonia-Prozesses 1963/64, in: Ulrich van der Heyden/llona Schleicher/Hans-Georg Schleicher (Hrsg.), Engagiert für Afrika. Die DDR und Afrika II, Münster/Hamburg 1994, S. 104ff. Zum Prozess selbst vgl. die folgenden ins Deutsche übersetzten Standardwerke: Hilda Bernstein, Die Männer von Rivonia. Südafrika im Spiegel eines Prozesses, Berlin 1970; Joel Joffe, Der Staat gegen Mandela. Die Jahre des Kampfes und der Rivonia-Prozeß, Berlin 2006.

10 Vgl. Ilona Schleicher, Prinzipien, Zwänge, Kalter Krieg. Die DDR und Sanktionen gegen Südafrika zu Beginn der 60er Jahre, in: Ulrich van der Heyden/Ilona Schleicher/Hans-Georg Schleicher (Hrsg.), Die DDR und Afrika. Zwischen Klassenkampf und neuem Denken, Münster/Hamburg 1993, S. 56 . 
des Selbstbestimmungsrechts der Völker voll unterstützte. „Dazu gehört auch“, so schrieb der DDR-Wissenschaftler Alfred Babing im Rückblick, „die konsequente Einhaltung des von den Vereinten Nationen verhängten Boykotts gegenüber den rassistischen und kolonialistischen Regimes." ${ }^{11}$

Dieser Boykott markierte den Beginn einer jahrelangen engen Unterstützung der DDR für den Kampf der südafrikanischen Befreiungsorganisation African National Congress (ANC) und der südafrikanischen Kommunisten gegen das Apartheidregime im Süden Afrikas. Die Art und Weise der Unterstützung der DDR war über die Jahrzehnte hinweg gesehen mannigfach, auch unterschiedlich intensiv oder ausgeprägt und hing nicht zuletzt von den politischen Gegebenheiten und Notwendigkeiten sowie - nicht zu vergessen - von den ökonomischen Potentialen der DDR ab. ${ }^{12}$ So aktivierte die DDR in der zweiten Hälfte der sechziger Jahre ihre Unterstützung für die internationale Propagandaarbeit sowie den bewaffneten Kampf der südafrikanischen Befreiungsorganisation ANC.. ${ }^{13}$ Das für die Entwicklungszusammenarbeit zentral zuständige Solidaritätskomitee der DDR finanzierte beispielsweise Mitarbeiter, die Druckkosten und den Vertrieb der offiziellen Zeitschrift des ANC, „Sechaba“, deren erste Ausgabe im Jahre 1967 erschien. Später wurde die Zeitung sogar in der DDR gedruckt ${ }^{14}$, ohne dass die SED, wie des Öfteren behauptet wurde ${ }^{15}$, Einfluss auf die inhaltliche Ausrichtung der Zeitung genommen hätte.

Eineinhalb Jahre nachdem die DDR die Produktion der „Sechaba“ übernommen hatte, wandte sich die SACP mit der Bitte an die SED, ihr im Jahre 1959 gegründetes Presseorgan „The African Communist“ ebenfalls in der DDR drucken zu lassen. Die SED sagte zu, da diese Form von Unterstützung den relativ begrenzten wirtschaftlichen Möglichkeiten der DDR am besten entsprach und ihr internationales Prestige nachhaltig steigern konnte.

Blieben diese Verbindungen bis in die 1960er Jahre der Öffentlichkeit weitgehend verborgen, so war die Berichterstattung über die Zusammenarbeit der DDR mit den südafrikanischen Befreiungsbewegungen in der Republik Südafrika sowie in Namibia, ANC und SWAPO, seit dem Besuch des DDR-Staats- und Parteichefs Erich Honecker in Afrika im Jahre 1979 offener. ${ }^{16}$ Schließlich wurden nach den bereits erwähnten Ereignissen von Soweto sogar relevante Publikationen aus der Bundesrepublik, die dort von südafrikanischen und bundesdeutschen Autoren veröffentlicht worden sind, in der DDR nachgedruckt oder in Lizenz hergestellt. ${ }^{17}$

${ }^{11}$ Alfred Babing, Einführung, in: Institut für Internationale Politik und Wirtschaft der DDR/DDRKomitee für die Kampfdekade gegen Rassismus und Rassendiskriminierung (Hrsg.), Gegen Rassismus, Apartheid und Kolonialismus. Dokumente der DDR 1949-1977, Berlin 1978, S.52.

${ }^{12}$ Vgl. die neueste zusammenfassendste Darstellung von Hans-Georg Schleicher, GDR Solidarity: The German Democratic Republic and the South African Liberation Struggle, in: The Road to Democracy in South Africa, Vol. 3: International Solidarity, Part 2, Pretoria/Hollywood 2008, S. $1069 \mathrm{ff}$.

${ }^{13}$ Vgl. Hans-Georg Schleicher/Ilona Schleicher, Waffen für den Süden Afrikas. Die DDR und der bewaffnete Befreiungskampf, in: Ulrich van der Heyden/Ilona Schleicher/Hans-Georg Schleicher (Hrsg.), Engagiert für Afrika, S. $7 \mathrm{ff}$.

${ }^{14}$ Vgl. Eric Singh, Sechaba. ANC-Zeitschrift Printed in GDR, in: Ebenda, S. 129ff.; Ilona Schleicher, Der lange Weg der Sechaba, in: Der Überblick. Zeitschrift für ökumenische Begegnung und internationale Zusammenarbeit, Nr. 4, 1990, S.81.

${ }^{15}$ Vgl. J. Jacobs, Die Loodsing en Bedryf van Sechabe, die voormalige amtlike Mondstuk van die ANC, in: Journal for Contemporary History, Nr. 2, 1993, S. $125 \mathrm{ff}$.

${ }^{16}$ Vgl. Winrich Kühne/Bernard von Plate, Two Germanys in Africa, in: Africa Report, Vol.25, 1980, S. 14.

${ }_{17}$ Vgl. beispielsweise Peter Magubane, Magubanes Südafrika, Berlin 1983; Zindzi Mandela/Peter Magubane, Schwarz wie ich bin. Gedichte und Fotos aus Soweto, Berlin 1986. 


\section{Private Kontakte und offizielle Beziehungen zwischen DDR-Bürgern und Südafrikanern}

Wenngleich für DDR-Verhältnisse, zumindest ab Mitte der 1970er Jahre, relativ viele Publikationen zur Südafrika-Thematik erschienen waren ${ }^{18}$, konnte das Informations- und Lesebedürfnis der DDR-Bürger über bestimmte Aspekte der südafrikanischen Vergangenheit und Gegenwart doch nicht voll befriedigt werden ${ }^{19}$. So gab es kaum originäre Reportagen $^{20}$ aus dem Land am Kap. Die Lücken in der Berichterstattung sowie die nicht immer authentischen Informationen aus der und über die RSA waren indes nicht allein fehlendem Willen der DDR geschuldet. Vielmehr hatten, so mussten es etwa 1976 zwei polnische Journalisten erleben, ,in der Republik Südafrika [...] Journalisten aus sozialistischen Ländern keinen Zutritt". ${ }^{21}$

Eine gewisse Stabilität in den Beziehungen zwischen dem ANC und der DDR und somit auch zwischen DDR-Bürgern und nunmehr verstärkt in die DDR einreisenden ANC-Exilanten ist mit einer „Vereinbarung zwischen dem Zentralkomitee der Sozialistischen Einheitspartei Deutschlands und dem Exekutivkomitee des Afrikanischen Nationalkongresses Südafrikas über Zusammenarbeit in den Jahren 1973-1974" entstanden. Dieses Dokument sah neben Festlegungen zum Delegationsaustausch, zu Beratungen, zum Austausch von Informationen, Dokumentationen und Publikationen, zur medizinischen Behandlung und einem vierwöchigen Ferienaufenthalt von jeweils zwei Mitgliedern des Exekutivkomitees des ANC in der DDR pro Jahr auch vor, dass „Kader“ des ANC a an Schulen der Massenorganisationen der DDR ausgebildet werden sollten. Darüber hinaus wurde das Solidaritätskomitee der DDR beauftragt, konkrete Vereinbarungen für weitere Kooperationen mit dem ANC zu treffen. ${ }^{22}$

Private Kontakte zwischen den in der DDR lebenden Exilanten und ostdeutschen Bürgern wurden von der DDR-Obrigkeit dagegen nicht gerade mit Wohlwollen betrachtet, konnten jedoch auch nicht verhindert werden. Briefkontakte hingegen zwischen DDRBürgern und in Südafrika lebenden Menschen waren aufgrund des Misstrauens der Geheimdienste beider Seiten so gut wie unmöglich. Dies führte dazu, dass selbst zu politisch oder familiär nahestehenden Personen kaum direkte Verbindungen gepflegt werden konnten, sondern in der Regel über Personen in Drittländern, vorzugsweise über Großbritan-

${ }^{18}$ Vgl. Peter Sebald, African Studies in the GDR helped by the ANC, in: Ulrich van der Heyden (Hrsg.), 75 Years of the African National Congress of South Africa - 75 Years of Struggle against Colonialism and Racism, Berlin 1988, S. $107 \mathrm{ff}$.

19 Keinesfalls war es jedoch so, wie der Pfarrer, DDR-Regimekritiker, (lettte) DDR-Minister für Abrüstung und Verteidigung und heutige CDL-Funktionär Rainer Eppelmann im Jahre 1992 nach einer Südafrika-Reise äußerte, dass man sich in der DDR nicht über die Probleme Südafrikas hätte objektiv informieren können. Vgl. Ulrich van der Heyden, Südafrika - Eppelmann warnte die Kirche vor Kommunisten. Blick durch die Parteibrille aufs Kap, in: Neues Deutschland vom 10.11.1992.

9) Die letzte originäre Reportage stammt von einem in der DDR lebenden und journalistisch lehrenden Schweizer, nämlich Jean Villian, Lnd so schuf Gott die Apartheid. Sechstausend Kilometer durch Südafrika, Berlin 1961. Spätere in der DDR veröffentlichte literarische Dokumente dieses Genres waren in der Regel Nachdrucke oder Ïbersetzungen aus dem Englischen, deren Verfasser der AntiApartheid-Bewegung nahestanden.

21 Zbígníew Domarancsk/Tadeusz. Wójcik, Vorhof der Hölle, Leipzig 1976, S. 7.

29 Vgl. Stiftung Archiv der Parteien und Massenorganisationen der DDR im Bundesarchiv (SAPMOBArch): J IV 2/2.035/147, Bl.65f.: Vereinbarung zwischen dem Zentralkomitee der Sozialistischen Einheitspartei Deutschlands und dem Exekutivomitee des Afrikanischen Nationalkongresses Südafrikas über Zusammenarbeit in den Jahren 1973-1974. 
nien, erfolgen mussten. Und in jenen Fällen, in denen direkte familiäre oder freundschaftliche Kontakte zwischen Bürgern der DDR und der Republik Südafrika aufrechterhalten wurden, war äußerste Vorsicht geboten. Als größtes Hindernis stellte sich hier aber nicht das übertriebene Sicherheitsdenken der DDR-Sicherheitsorgane, sondern die südafrikanische Gesetzgebung, vor allem der Anticommunism Act heraus. Aus diesem Grunde vereinbarten etwa kirchliche Stellen der DDR mit den ostdeutschen Grenzorganen, dass zu Besuch in der DDR einreisende Südafrikaner keine Visa-Stempel in ihre Reisedokumente erhielten.

Auch andere südafrikanische Bürger, die die DDR, beispielsweise während der Weltfestspiele der Jugend und Studenten 1973, besuchen wollten, machten von dieser Möglichkeit Gebrauch. ${ }^{23}$ Besonders wichtig war es für die zur militärischen Ausbildung oder zu medizinischen Zwecken in der DDR weilenden ANC-Kader, keinen Stempel in die Reisedokumente zu erhalten. Der letzte stellvertretende Leiter des ANC-Büros in Ostberlin, Indres Naidoo, schreibt dazu in seinen Lebenserinnerungen: „Sie [die Freiheitskämpfer des ANC - U. v. d. H.] kamen und gingen, ohne einen Stempel im Pass zu erhalten. Ein Stempel der DDR hätte verheerende Folgen in Südafrika nach sich ziehen können. “24

Andere, in der Regel „weiße“ Bürger der Republik Südafrika, die nicht einmal Sympathisanten des ANC waren, die zu Hause durch einen Besuch in einem „kommunistischen Land" nicht gefährdet waren, also nicht unter den restriktiv gehandhabten Anticommunism Act des Apartheidregimes fielen, konnten sich hingegen wie andere westliche Touristen in der DDR bewegen. Das Ministerium für Staatssicherheit (MfS) registrierte allerdings etwa im Jahre 1977 gerade einmal 60 Besucher aus Südafrika, ohne hier zwischen ANCMitgliedern und „normalen“ Touristen zu unterscheiden. ${ }^{25}$

Umgekehrt war ein Besuch von DDR-Bürgern im Land am Kap bis nach Mitte der 1980er Jahre vollkommen unmöglich, selbst wenn trot $z$ der bekannten rigiden Reisebeschränkungen seitens der DDR einige ihrer Staatsbürger hätten dorthin reisen können, so wie ja auch vereinzelte Privatreisen nach Australien und anderen Ländern möglich waren. Denn das Apartheidregime hatte im Allgemeinen ein kaum weniger rigides Reise- und Grenzregime als die DDR. Demzufolge verwundert die Feststellung nicht, dass zum Ende der 1970er bzw. zu Beginn der 1980er Jahre, nach einer Recherche des MfS, sich keine Staatsbürger der DDR in der Republik Südafrika aufhielten. ${ }^{26}$

Nach vielen Jahren des Einreiseverbots reiste buchstäblich als erster offizieller DDRBürger der Ostberliner Rechtsanwalt und Beauftragte Erich Honeckers für humanitäre Fragen, Wolfgang Vogel, in den 1980er Jahren für drei Tage nach Südafrika, um einen letztlich erfolglos gebliebenen - Versuch zu unternehmen, Nelson Mandela gegen den sowjetischen Regimekritiker Andrej Sacharov auszutauschen. ${ }^{27}$ Im Jahre 1987 besuchte der Pfarrer Helmut Schiewe mit Genehmigung der DDR-Regierung die Republik Südafrika. ${ }^{28}$

23 Vgl. Die Bundesbeauftragte für die Unterlagen des Staatssicherheitsdienstes der ehemaligen Deutschen Demokratischen Republik (BStU): MrS-Zentralarchiv, HVA, Nr. 188, Bl. 38.

24 Indres Naidoo, Robben Island - Insel in Ketten, Göttingen ²003, S. 289.

25. Vgl. BStU: MtS-Zentralarchiv, HA II, Nr.28725, Bl. 4.

26 Vgl. BStU: MrS-Zentralarchiv, HA IX, Nr. 10020, Bl. 50.

27 Vgl. Albrecht Hagemann, Nelson Mandela, Reinbek bei Hamburg 1995, S. 108.

2s Vgl. Helmut Schiewe, Eine Reise nach Südafrika 1987. Eindrücke und Erlebnisse eines Kirchenmannes aus der DDR, in: Ulrich van der Heyden/Ilona Schleicher/Hans-Georg Schleicher (Hrsg.), Engagiert für Afrika, S.94ff. 
Später nahm die stellvertretende Chefredakteurin der Tageszeitung ,Junge Welt“, Karin Retzlaff, aufgrund einer entsprechenden Einladung sowie nach Absprache mit dem ANC und mit ausdrücklicher Genehmigung des SED-Politbüros, an der Konferenz „Der Konflikt in Südafrika und die Presse" in Johannesburg teil. ${ }^{29}$

Dies dürften vor der politischen Wende in der DDR 1989/90 seit Anfang der 1960er Jahre, als sich der ostdeutsche Staat offiziell den Sanktionen gegen das Apartheidregime angeschlossen hatte ${ }^{30}$, die einzigen offiziellen Besucher der DDR in Südafrika gewesen sein. Ausnahmen bildeten lediglich Notfälle, wenn etwa ein Matrose auf einem DDR-Handelsschiff dringende medizinische Hilfe benötigte oder DDR-Bürger bei privaten Besuchen im Westen Deutschlands ihren DDR-Reisepass in einen aus der Bundesrepublik eintauschten und so ausgestattet in den Süden Afrikas flogen.

Kurz vor dem Ende der DDR gab es indes einige noch wenige Jahre zuvor kaum vorstellbare Kontakte zwischen DDR-Bürgern und Bürgern Südafrikas, die nicht der Befreiungsorganisation ANC oder anderen gebannten Organisationen wie der SACP angehörten. So kamen, wenn auch nur vereinzelt nachweisbar, „weiße Touristen“ in die DDR, die vor allem ihren „deutschen Wurzeln“ nachspüren wollten, wie etwa der damalige Generalsekretär der Deutsch-Südafrikanischen Kulturvereinigung. Im Jahre 1987 wurde nicht zuletzt aus diesem Grunde ein "neuer Trend“ in der Afrikapolitik der DDR von westlichen Beobachtern bemerkt. ${ }^{31}$ Zum ersten Male waren zudem in jenem Jahre „weiße“ Journalisten aus Südafrika in die DDR eingeladen worden.

Eine Besonderheit stellte zweifellos das Studium einer südafrikanischen weißen Studentin an der Musikhochschule Leipzig von 1962 bis 1969 dar, die sogar ein Leistungsstipendium der DDR bezog. Ihrer eigenen Aussage in einem Interview mit dem Autor zufolge habe sie sich in der DDR „unpolitisch“ verhalten und auch keinen Kontakt zur ANC-Community in der Messestadt gepflegt. Die damalige Studentin will zudem die Apartheid öffentlich gelobt und für ein „Nebeneinander der Kulturen“ anstelle einer „Kulturmischung“ plädiert haben. Im Rückblick lobte sie die ostdeutschen Bürger im Vergleich mit den „amerikanisierten Westdeutschen“ dafür, dass sie „deutsch“ geblieben seien! ${ }^{32}$

\section{Die DDR und der internationale Boykott des Apartheidregimes}

Einheimische und internationale Gegner des Regimes in Südafrika hatten bereits seit Mitte der 1950er Jahre für einen internationalen Warenboykott plädiert, um auf diese Weise gegen die menschenverachtende, undemokratische und rassistische Politik der Apartheid zu protestieren und um wirtschaftlichen Druck auf die weiße Bevölkerungsminorität auszuüben.

Auf dem ersten Allafrikanischen Völkerkongress in Accra (Ghana) im Dezember 1958 war ein Aufruf des ANC: zum weltweiten Boykott südafrikanischer Waren verabschiedet

\footnotetext{
99 Vgl. Bettina Husemann/Annette Neumann, Die Afrikapolitik der DDR. Eine Titeldokumentation von Akten des Politbüros und des Sekretariats des Zentralkomitees der SED 1949-1989, Hamburg 1994, S. 221.

30 Vgl. Ilona Schleicher, Zur Diskussion um die Beteiligung der DDR an Sanktionen gegen Südafrika Anfang der sechziger Jahre, in: Afrika Spectrum, Nr. 3, 1990, S. $283 \mathrm{ff}$.

${ }^{31}$ Vgl. DDR - Südafrika, in: Internationales Afrikaforum, Nr. 1, 1988, S. 5.

${ }^{32}$ Interview mit L.J. (vollständiger Name ist dem Verfasser bekannt - U. v. d. H.) am 3.9.2002 in Pretoria.
} 
worden. ${ }^{33}$ Während sich die sozialistischen Länder in den folgenden Jahren nahezu geschlossen dem Aufruf zum Boykott anschlossen, unterstützten die meisten Regierungen der westlichen Welt den Boykottaufruf nicht oder nur formal. Das änderte sich im Verlaufe von gut drei Jahrzehnten kaum. So gehörten (und blieben es bis zum Schluss) nach UNOAngaben Großbritannien, die USA, Japan und die Bundesrepublik Deutschland zu den Haupthandelspartnern des Apartheidregimes. ${ }^{34}$ Erst gegen Mitte der 1980er Jahre wurde der Boykottdruck des Westens auf das Apartheidregime verstärkt.

Die DDR benötigte Ende der 1950er Jahre/zu Beginn der 1960er Jahre einige Zeit an Überlegungen und nicht zuletzt an politischem Druck durch ihre südafrikanischen Verbündeten, bevor sie sich dem Boykott anschloss.

Bereits Anfang des Jahres 1960 hatten Führungsmitglieder der SACP bei Gesprächen in der DDR mit hochrangigen Vertretern der SED die Boykottfrage angesprochen und versucht, das ostdeutsche Land davon zu überzeugen, alle Handelskontakte mit dem Rassistenregime abzubrechen. ${ }^{35}$ Gut ein Jahr später stand die Frage der Beteiligung der DDR an der Boykottbewegung erneut auf der Tagesordnung. Weitere Gespräche mit Vertretern der SACP führten dazu, dass das Außenministerium der DDR von der SED-Führung beauftragt wurde, sich in dieser Hinsicht mit den anderen sozialistischen Ländern abzustimmen. ${ }^{36}$

Ein damaliger hochrangiger SACP-Funktionär, Vella Pillay, hatte führenden DDR-Genossen mehrfach erklärt, dass unter Berücksichtigung der ökonomischen Probleme der DDR und deren Exportinteressen es bei den Kommunisten Südafrikas durchaus Verständnis dafür gäbe, wenn die DDR nicht sofort alle Handelskontakte zum Rassistenregime abbrechen würde - es genüge, so Pillay, wenn zunächst vorrangig die Importe aus Südafrika reduziert werden könnten. ${ }^{37}$ Damit hatten die Konsultationen mit der SACP tatsächlich dazu beigetragen, „die Handelspolitik der DDR gegenüber Südafrika zu korrigieren und größere Anstrengungen von Seiten der Handelsorgane zu erreichen, sich der internationalen Boykottbewegung anzuschließen ". ${ }^{38}$

Die DDR, die sich auf diplomatischer Ebene und in der Öffentlichkeit immer wieder solidarisch mit den nationalen Befreiungsbewegungen in der Dritten Welt erklärt hatte, befand sich in einem Dilemma. Zum einen war sie der Auffassung, so der stellvertretende DDR-Außenminister in einem internen Schreiben, „dass die Südafrikanische Republik unter dem Verwoerd-Regime mit aktiver Unterstützung Großbritanniens, der USA und Westdeutschlands zu einem Stützpunkt des Imperialismus in Afrika, zu einer Aggressionsbasis gegen die unabhängigen Staaten Afrikas und zu einer tödlichen Gefahr für die noch um ihre Befreiung vom Kolonialismus kämpfenden afrikanischen Völker geworden ist “" ${ }^{39}$ Auf der anderen Seite sei Südafrika seit Ende der 1950er Jahren nach Ägypten das wichtigste afrikanische Export-Land für DDR-Waren. Bis zum Jahre 1957 war Südafrika sogar das zweit-

\footnotetext{
${ }^{33}$ Vgl. Ilona Schleicher, Prinzipien, S. 45.

34 Ein Verbrechen gegen die Menschheit. Fragen und Antworten über Apartheid in Südafrika, hrsg. von den Vereinten Nationen, o. O. 1973, S. 30.

35 Vgl. Ilona Schleicher/Hans-Georg Schleicher, Die DDR im südlichen Afrika. Solidarität und Kalter Krieg, ${ }^{2}$ Hamburg 1998, S. 10 f.

36 Vgl. SAPMO-BArch: DY 30/IV2/2078 (o. P.): Protokoll der Sitzung der APK am 6. 2. 1961, Bl. $1 \mathrm{ff}$.

37 Vgl. Ilona Schleicher/Hans-Georg Schleicher, Die DDR im südlichen Afrika, S. 12.

38 SAPMO-BArch: DY 30/IV 2/20/410 (o. P.): Bericht über Beziehungen zu den Bruderparteien südlich der Sahara.

39 Politisches Archiv des Auswärtigen Amts (PA AA): Bestand MfAA: A 001168, Fiche 2/4, Bl. 121: Stellungnahme des stellvertretenden Ministers für Auswärtige Angelegenheiten der DDR, Dr. Wolfgang Kiesewetter [um 1964].
} 
bedeutendste afrikanische Import-Land für die ostdeutsche Wirtschaft gewesen. ${ }^{40}$ Auch nach 1959 - also bereits ein Jahr nach dem internationalen Aufruf zum Handelsboykott entwickelten sich die DDR-Exporte nach Südafrika auf relativ hohem Niveau weiter.

Diese Tatsache sollte jedoch möglichst vor der Öffentlichkeit geheim gehalten werden. In einem Brief von 14. März 1961 an das Ministerium für Auswärtige Angelegenheiten der DDR (MfAA) findet sich die Mitteilung, dass bei der Durchsicht des Statistischen Taschenbuches der DDR von 1960 aufgefallen sei, dass der Handel mit der Südafrikanischen Union darin aufgeführt war. Es folgte der Vorschlag, in Zukunft in der Statistik eine Rubrik für „weitere Länder“ zu schaffen, in der dann die Südafrikanische Union mit erfasst werden könne. „Eine solche Veröffentlichung, wie sie im o.g. Statistischen Taschenbuch erfolgte, bringt uns politische Schwierigkeiten mit den demokratischen Kräften der Südafrikanischen Union, die einen Boykott der Südafrikanischen Union fordern. Wenn wir uns schon aus ökonomischen Gründen einem solchen Boykott nicht anschließen können, so sollten wir darauf verzichten, unseren Handel mit der Südafrikanischen Union zu propagieren. ${ }^{41}$

Offensichtlich befand sich die DDR in dieser Hinsicht in einem beständig starken Konflikt, denn einerseits musste die eigene ökonomische Situation durch internationale Handelsbeziehungen verbessert werden und andererseits wollte sie die südafrikanische Befreiungsbewegung mit dem Handelsboykott politisch unterstützen. ${ }^{42}$ Da so einfach aus dieser Misere kein Ausweg zu finden war, beeilte sich die SED bzw. die DDR nicht unbedingt mit einer Auflösung dieses Widerspruchs.

Der Versuch der DDR trotz Sympathiebekundungen für den ANC die Handelsbeziehungen zur Südafrikanischen Union weiterhin aufrechtzuerhalten, wurde von den westlichen Medien mit entsprechenden Schlagzeilen begleitet. So hatte am 15. September 1959 die „Süddeutsche Zeitung“, zwei Tage darauf die „Frankfurter Allgemeine Zeitung“ sowie die französische Nachrichtenagentur AFP von einer Reisedelegation ostdeutscher Außenhandelsvertreter auf dem Weg nach Südafrika berichtet. Solche Meldungen trafen die DDR an ihrer empfindlichsten Stelle, zumal ihre Anti-Apartheid-Propaganda auch ein Mittel darstellte, den außenpolitischen Alleinvertretungsanspruch der Bonner Regierung zu durchbrechen und internationale Anerkennung zu gewinnen. Die Handelsdelegation wurde deshalb nach Bekanntwerden ihres Reiseziels von der Ostberliner Regierung umgehend zurückbeordert. ${ }^{43}$

Doch auch nach diesem Ereignis schrieb die „Westpresse“ über angeblich weiterhin existierende ostdeutsche Handelsbeziehungen zu Südafrika. Die Beziehungen zwischen der SED und der SACP bzw. dem ANC wurden dadurch stark belastet. Unterdessen verstärkte sich der internationale Boykottdruck weiterhin, als sich die Organisation Afrikanischer Staaten (OAU) nach verstärkten Aktionen der internationalen Staatengemeinschaft dem Boykottaufruf gegen das Apartheidregime anschloss. ${ }^{44}$ Es fiel der DDR aufgrund der Bedeutung Südafrikas als Handelspartner immer noch sehr schwer, sich sofort vollständig

\footnotetext{
41) Vgl. Statistisches Jahrbuch der DDR 1959, Berlin 1960, S.574. Die folgenden Ausführungen stützen sich zum größten Teil auf die Publikation von Ilona Schleicher, Prinzipien, S. 58, sowie auf dies./HansGeorg Schleicher, Die DDR im südlichen Afrika, S. 4-23.

41 PA AA: Bestand MfAA: A 11183, Bl.41: Schüssler in einem Brief an die 4. Außereuropäische Abteilung des Ministeriums für Auswärtige Angelegenheiten, 14.3.1961.

42. Vgl. Ilona Schleicher, Prinzipien, S. 46.

4:3 Vgl. ebenda.

${ }^{44}$ Vgl. Gerhard Kramer, Portugal am Pranger. Der portugiesische Kolonialismus - Feind der Völker Afrikas, Berlin 1964, S. $131 \mathrm{ff}$.
} 
den Boykottwünschen anzuschließen, zumal einige Länder, beispielsweise die Bundesrepublik, diese ignorierten.

So war seit 1960 die Boykottfrage immer wieder eines der Hauptthemen bei Gesprächen zwischen der SED und der SACP. Südafrikas Kommunisten äußerten hierbei deutlich ihre Enttäuschung über die Haltung der DDR und anderer sozialistischer Staaten, die sich auch nach der UN-Resolution vom 6 . November $1962^{45}$ noch nicht der internationalen Boykottbewegung angeschlossen hatten. ${ }^{46}$

Berichte in der Johannesburger Zeitung „Sunday Times“ vom 19. Mai 1963 mit dem Titel „Rote Waffenhändler werben in Südafrika“ oder im Londoner "Sunday Telegraph“ vom 2. Juni 1963 erhöhten die politischen Spannungen zwischen SED und der SACP bzw. ANC noch einmal. In jenen Zeitungsartikeln wurde behauptet, dass die ČSSR und die DDR nicht unbedeutende Mengen von Gewehren und Munition nach Südafrika liefern würden und zudem besonderes Interesse an einem Ausbau des Waffenhandels bekundet hätten. Die DDR würde dabei südafrikanischen Waffenfirmen Handfeuerwaffen zu besseren Konditionen als westliche Länder anbieten; Länder wie Schweden, Dänemark, Italien und Kanada hätten inzwischen den Export von leichten Waffen nach Südafrika dagegen sogar ganz eingestellt. ${ }^{47}$

Auf den erwähnten Artikel im „Sunday Telegraph“ reagierte der damalige Vertreter des ANC in London, Maindy Msimang, mit einem persönlichem Brief an den damaligen DDRStaats- und Parteichef Walter Ulbricht, in dem es u. a. hieß: „Es fällt uns daher schwer zu verstehen, wieso sich die friedliebende Bevölkerung der Deutschen Demokratischen Republik in das Kriegstreiben der südafrikanischen Faschisten einspannen lassen sollte, insbesondere nachdem Ihr Land und Ihre Landsleute in letzter Vergangenheit unter dem Nazismus die ganzen Schrecken des Krieges und der Zerstörung miterlebt haben. Wir bedauern und verurteilen den Waffenhandel mit dem faschistischen Südafrika, weil eine derartige Zusammenarbeit nicht nur die Tendenzen zur Niederwerfung der Bestrebungen unseres Volkes verstärkt und unterstützt, sondern auch die imperialistische Beherrschung Afrikas im allgemeinen und Südafrikas im besonderen stärkt und ausweitet. ${ }^{48}$ Msimang bat in dieser Angelegenheit den DDR-Chef um eine Stellungnahme. Der Brief sorgte für Unruhe und Unsicherheit unter den DDR-Politikern und -Außenhändlern. Zunächst einmal wurde ein über Frankreich angeschobenes lukratives Geschäft über den Verkauf von 30 bis 40 EisenbahnKühlwagen in die Südafrikanische Union aller Wahrscheinlichkeit nach sofort storniert. ${ }^{49}$

So setzte in der DDR-Führung erst unter äußerem Druck die Diskussion um eine konsequente Durchsetzung von Boykottmaßnahmen gegen Südafrika ein. ${ }^{50}$ Der stellvertretende

45 In der Resolution wurde der UN-Sicherheitsrat aufgefordert, Sanktionen gegen Südafrika zu verhängen und es gegebenenfalls seines nicht-ständigen Sitzes im Sicherheitsrat zu entheben. Den UNMitgliedstaaten wurde empfohlen, bestehende diplomatische Beziehungen zu Südafrika abzubrechen, Häfen und Flughäfen für südafrikanische Schiffe und Flugzeuge zu sperren, desgleichen südafrikanische Häfen und Flughäfen zu boykottieren, auf den Import südafrikanischer Waren zu verzichten und keine Güter mehr nach Südafrika zu exportieren. Insbesondere sollte der Transport von Waffen und Munition nach Südafrika unterbunden werden. Vgl. Resolution: Die Apartheid-Politik der Südafrikanischen Republik vom 6.11.1962, in: Büro der deutschen Liga für die Vereinten Nationen (Hrsg.): UNO-Bilanz 1962/63, Berlin 1963, S.85ff.

46 Vgl. Ilona Schleicher, Prinzipien, S.49f.

47 Vgl. ebenda, S. 53.

48 PA AA: Bestand MfAA: A 16048, BI. 3.

49 Vgl. BStU: MfS-Zentralarchiv, AIM 4004/73 (o. P.): Information, Leipzig, 6. 3. 1963.

${ }^{50} \mathrm{Vgl}$. Ilona Schleicher/Hans-Georg Schleicher, Die DDR im südlichen Afrika, S. 15 . 
Außenminister der DDR schrieb am 8.Juni 1963 an den Außenhandelsminister Julius Balkow: „Die afrikanischen Völker und alle fortschrittlichen Kräfte der Welt fordern immer stärker Boykottmaßnahmen. Auch die Deutsche Demokratische Republik ist mehrfach in internationalen Stellungnahmen als konsequente Verfechterin der nationalen Interessen der um ihre Freiheit kämpfenden Völker des afrikanischen Kontinents und gegen die Politik der Apartheid in Südafrika aufgetreten. Der Handel mit Südafrika und das Anlaufen portugiesischer und südafrikanischer Häfen durch die neue Ostafrika-Schiffslinie der DDR schädigen das Ansehen der DDR und bieten den Imperialisten die Möglichkeit, die DDR zu diskriminieren ${ }^{51}$ und unsere Politik zu verleumden. ${ }^{\text {"52 }}$ Er schlug vor, den Export nach und den Import aus Südafrika sowie alle Reisen dorthin einzustellen und forderte eine schnelle Entscheidung. Der damalige Leiter der Abteilung Internationale Verbindung des ZK der SED, Peter Florin, unterstrich in einem Schreiben an die Abteilung Handel, Versorgung und Außenhandel des ZK der SED, dass ,im Interesse des Ansehens der DDR und nicht zuletzt im Interesse des Handels der DDR mit den afrikanischen Staaten eine Überprüfung unseres Handels mit Südafrika erforderlich ist" ".53

Als ein Ergebnis der internen Diskussionen wurde am 22. Juni 1963 eine Erklärung der Presseabteilung des Ministeriums für Außenhandel und Innerdeutschen Handel der DDR verbreitet, die die „verlogenen Meldungen verschiedener Agenturen und Zeitungen imperialistischer Mächte“ als „Falschmeldungen“ zurückwies. Diese zielten, wie es hieß, nur auf die Ablenkung von der „engen wirtschaftlichen und militärischen Zusammenarbeit der EWG- und NATO-Staaten, darunter auch Westdeutschlands“ mit Südafrika. Das Ministerium beteuerte, dass „zwischen der DDR und Südafrika [...] keinerlei offizielle Verträge oder Vereinbarungen über den Waren- und Zahlungsverkehr“ bestünden. „Ein Abschluss solcher Verträge und Vereinbarungen ist auch in keiner Weise beabsichtigt. " 54

Die Waffen, von denen in den Artikeln des „Sunday Telegraph" und der „Sunday Times“ berichtet worden waren, stammten aus Suhl. Dabei handelte es sich indes nicht um militärisches Gerät, sondern lediglich um Handfeuerwaffen für die Jagd. Der Export dieser Jagdwaffen und der dazugehörigen Munition wurde dennoch sofort eingestellt. ${ }^{55}$

Kurze Zeit später betonte der Minister für Auswärtige Angelegenheiten der DDR, Lothar Bolz, in einem Brief an den Vorsitzenden der Anti-Apartheid-Kommission der UNO, „dass zu keiner Zeit militärische Waffen, Geräte usw. jemals ausgeliefert wurden. Die Regierung und die Bevölkerung der Deutschen Demokratischen Republik stehen fest an der Seite der Bevölkerung Südafrikas im Kampf gegen das dortige Terror- und Apartheidregime. Niemals wird die Deutsche Demokratische Republik den Befreiungskampf verraten, sondern auch in Zukunft mit allen ihr zu Gebote stehenden Mitteln unterstützen." ${ }^{\text {“5 }}$

Daraufhin konnte die Abteilung Internationale Verbindungen des ZK der SED in einer Konzeption zur Verbesserung der Beziehungen zu Südafrikas Kommunisten feststellen: „Durch den Abbruch der Handelsbeziehungen der DDR und der Republik Südafrika ist

5l Gemeint ist möglicherweise „diskreditieren“.

52 PA AA: Bestand MfAA: A 16048 (o. P.): Brief von Schwab an Balkow, 8.6. 1963.

53 Vgl. SAPMO-BArch: DY 30/IV A 26. 10/332 (o. P.).

${ }^{54}$ Westliche Zwecklügen über Handelsbeziehungen DDR - Südafrika, in: Neues Deutschland vom 23.6. 1963 .

55 Vgl. Ilona Schleicher, Prinzipien, S.56.

5t) PA AA: Bestand MfAA: A 16048, Bl. 20f.: Brief von Dr. Lothar Bolz, Minister für Auswärtige Angelegenheiten der DDR, 30.7.1963. 
ein entscheidendes Hindernis für die Aktivierung der Beziehungen zwischen unseren beiden Parteien beiseite geräumt. “57

War man in der Bundesrepublik Deutschland vor allem an einer „Wiederbelebung der traditionellen deutsch-südafrikanischen Beziehungen" interessiert ${ }^{58}$, so war es auch für den Außenhandel der DDR keine leichte Entscheidung, sich dem Boykott anzuschließen.

Denn einerseits ging man der dringend benötigten mit Südafrika erwirtschafteten Devisen verlustig, und andererseits mussten auch die lukrativen Märkte in der Republik Südafrika - so die offizielle Bezeichnung ab dem 1.Juni 1961 - aufgegeben werden. Ein Beschluss der Außenpolitischen Kommission (APK) beim Politbüro des ZK der SED vom 5. Juli 1963 trug dieser Situation Rechnung, indem er zunächst ausdrücklich nur die direkten Geschäftskontakte der DDR-Außenhandelsbetriebe mit Südafrika unterband. Damit war von kompetenter Stelle eine Entscheidung getroffen worden, nach der sich die betreffenden staatlichen Institutionen der DDR zu richten hatten.

Handel DDR - Südafrika in den Jahren 1958-1963 (Angaben in Millionen Valuta Mark) ${ }^{59}$

\begin{tabular}{lrrrrrr}
\hline Jahr & 1958 & 1959 & 1960 & 1961 & 1962 & 30.4 .1963 \\
\hline Export & 9,6 & 8,4 & 7,3 & 6,5 & 6,7 & 6,7 \\
Import & 1,4 & 1,1 & 1,6 & 13,3 & 0,2 & - \\
\hline
\end{tabular}

Dass es sofort nach diesem Beschluss tatsächlich zum Abbruch der Handelsgeschäfte gekommen ist, ist eher unwahrscheinlich. Denn dies hätte ja einen noch höheren finanziellen Verlust bedeutet, etwa durch Vertragsstrafen, als die Beteiligung an den Sanktionen ohnehin den Staatshaushalt der DDR gekostet hat.

In Ostberlin wurden jedoch die Weichen für eine endgültige Entscheidung über die Frage, wie man in dieser nicht leicht zu lösenden Situation zukünftig verfahren solle, auf der Sitzung der APK am 5.Juli 1963 gestellt. ${ }^{60}$ Das Außenministerium hatte in Vorbereitung auf die entscheidende Sitzung der APK eine Stellungnahme zum Handel mit Südafrika verfasst und aus der internationalen Sanktionsdiskussion folgende Schlussfolgerungen gezogen: „Die eminent wichtige Frage Südafrika wurde auch vom Imperialismus erkannt. Um seine wahren Absichten zu verschleiern, werden in Erklärungen Bezeugungen der Sympathie für den Befreiungskampf der Afrikaner in ganz Afrika abgegeben. Nur so kann man die Forderung des Internationalen Bundes Freier Gewerkschaften (IBFG) an alle UNO-Mitgliedstaaten, die diplomatischen und Handelsbeziehungen zur Südafrikanischen Republik ab7ubrechen, verstehen [...]. In einem Grußschreiben an den ANC Südafrikas bringt der SPD-Vorstand zum Ausdruck, dass die SPD für die Freiheit aller Völker und gegen jede Form der Diktatur und den Kolonialismus sei und der Kampf um die Freiheit des Menschen in Südafrika ihre volle Unterstützung fände. Angesichts einer solchen Entwicklung erscheint es umso wichtiger, dass die afrikanischen Völker ihre wahren Freunde, die sozialistischen Länder, erkennen. Die geringsten Blößen, die sich die Deutsche Demokratische Republik in ihrer Haltung zur Südafrika-Frage gibt, werden ohne Zweifel sofort von

57 SAPMO-BArch: DY 30/IV A2/20/985 (o. P.).

58 Vgl. Albrecht Hagemann, Bonn und die Apartheid in Südafrika. Eine Denkschrift des Deutschen Botschafters Rudolf Holzhausen aus dem Jahr 1954, in: Vierteljahrshefte für Zeitgeschichte 43 (1995), S. 679-706.

59 Tabelle aus Ilona Schleicher/Hans Georg Schleicher, Die DDR im südlichen Afrika, S. 21.

fi) Die folgenden Ausführungen stützen sich auf ebenda, S. $17 \mathrm{ff}$. 
den Bonner Machthabern ausgenutzt, um den Kampf der Afrikaner von sich abzulenken und die Deutsche Demokratische Republik gegenüber den afrikanischen Völkern zu verleumden. In Wahrung der Prinzipien des proletarischen Internationalismus und im Interesse des Ansehens der DDR unter den afrikanischen Ländern ist daher eine Revision des gegenwärtigen Zustandes notwendig. " ${ }^{61}$

Trotz der Grundsatzentscheidung fanden einzelne DDR-Produkte auch weiterhin über Drittstaaten ihren Weg nach Südafrika; dabei ist unklar, ob dies mit oder ohne Wissen der DDR-Verantwortlichen geschah. ${ }^{62}$ Aufgrund vielfältiger, aber unbewiesener Anschuldigungen sah sich die DDR im Mai 1964 schließlich veranlasst, offiziell zu erklären, dass „die von der Westpresse verbreiteten Meldungen über einen angeblich ständig wachsenden Handelsaustausch und Schiffsverkehr zwischen der DDR und der Republik Südafrika [...] jeder Grundlage“ entbehren. ${ }^{63}$ Und in einer Publikation des Solidaritätskomitees der DDR aus jener Zeit heißt es: „Die DDR hat das faschistische Apartheid-Regime von Südafrika [...] niemals anerkannt und unterhält auch keinerlei Beziehungen zu diese[m] Regime." ${ }^{\text {"64 }}$

Ungeachtet des offiziellen Dementis gab es, wie es scheint, weiterhin Möglichkeiten zur Umgehung des Boykottbeschlusses. Jedoch handelte es sich keineswegs um direkte Handelsbeziehungen, sondern um nahezu konspirative, indirekte Handelskontakte.

Ein Beispiel für den Transfer ostdeutscher Produkte nach Südafrika über Dritte stellt der „Wartburg“ dar. Das Auto war bereits in den 1950er Jahren auf dem südafrikanischen Markt zu erhalten, und sein Verkauf wurde auch nach dem offiziellen Boykottbeschluss der DDR nicht eingestellt. ${ }^{65}$ Der Vertrieb wurde über Belgien und die Niederlande abgewickelt. Anfang der 1970er Jahre kam sogar noch der Campinganhänger „Alpenkreuzer“ dazu. Ob der DDR-Seite der Weiterverkauf durch den Käufer ihrer Produkte nach Südafrika bekannt war, muss offenbleiben. Da sowohl die Autos als auch der Anhänger ausschließlich von kleineren, namenlosen Handelsgesellschaften im Süden Afrikas vertrieben worden waren, die wenig Geld für Werbung ausgaben und deren Besitzer auch häufig wechselten, blieb der Absatz begrenzt und somit auch der Bekanntheitsgrad der ostdeutschen Produkte. Der DDR blieben unangenehme Nachfragen sowie politische und diplomatische Schwierigkeiten erspart. Für die südafrikanischen Besitzer waren die Erzeugnisse nicht direkt als Produkte der DDR zu erkennen. Auskunft gebende Markenzeichen waren entfernt worden. Erst beim Auftreten erster Verschleißerscheinungen, etwa wenn die „Pneumant“-Räder (die Marke der DDR-Reifen) oder die mit „Made in GDR“ gekennzeichneten Kugellager ausgewechselt werden mussten, wurde deutlich, dass der Anhänger oder das Auto nicht aus einem westeuropäischen Unternehmen stammte, sondern aus der DDR. ${ }^{66}$

So gab es also in der Vergangenheit eine Reihe von Vermutungen und Rätselraten, ob die DDR sich an das Boykott-Gebot hielt oder nicht, ob der Weiterverkauf von DDR-Pro-

61 SAPMO-BArch: DY 39/IV A2/20/987 (o. P.): Stellungnahme der 4. Außereuropäischen Abteilung (AEA) zu den Problemen des Handels mit Südafrika, 3.7.1963 (Abschrift).

62 Fakt ist lediglich, dass die westliche Presse, vor allem diejenige aus der Bundesrepublik, 7umindest anfangs nicht müde wurde, der DDR vorzuwerfen, sie unterhalte trotz anderslautender Propaganda weiterhin Handelsbeziehungen zum Apartheidstaat. Bewcise konnten allerdings nicht vorgelegt werden.

${ }^{63}$ Kein Handel DDR - Südafrika, in: Neues Deutschland vom 13.5. 1964.

${ }^{64}$ Alfred Babing, Nationaler Befreiungskampf im südlichen Afrika, hrsg. vom Solidaritätskomitee der DDR, Berlin o. J., S. 43.

${ }^{65}$ Vgl. Hans Heese, Trotz Sanktionen - DDR Fahrzeuge rollen in Südafrika, in: Ulrich van der Heyden/Ilona Schleicher/Hans-Georg Schleicher (Hrsg.), Engagiert für Afrika, S. 78.

6i Vgl. ebenda, S. 79. 
dukten durch westliche Händler an das Apartheidregime von DDR-Seite hätte verhindert werden können oder nicht. Bis in die Zeit der Archivöffnungen in der früheren DDR konnte auch in der wissenschaftlichen Forschung kein abschließendes Urteil gefällt werden.

Mehr Licht in die Frage, ob es trotz. offizieller Boykott-Beteiligung langfristige indirekte Handelskontakte zwischen der DDR und Südafrika gegeben hat, können interne Dokumente des MfS und der Abwehr des Ministeriums für Nationale Verteidigung der DDR bringen. Generalmajor Krause, der Leiter des Militärgeheimdienstes der DDR, warnte das MfS am 17. Juni 1983, dass eigenen Erkenntnissen zufolge die NATO ein Dokument über angebliche Rohstoffexporte der DDR und Polens nach Südafrika vorbereite. Der Chef der NVA-Abwehr schrieb: „Alle Vertretungen der NATO in den sozialistischen, nichtpaktgebundenen und neutralen Staaten wurden aufgefordert, Informationen und ,Beweise“ über alle direkten und indirekten Kontakte der sozialistischen Staaten zu Südafrika zusammenzutragen." ${ }^{67}$ Das MfS leitete umgehend eigene Untersuchungen ein und stellte in einem Brief des stellvertretenden Ministers für Staatssicherheit, Generalleutnant Rudi Mittig, an den Leiter der Hauptverwaltung Aufklärung des MfS, Generaloberst Markus Wolf, fest, dass „die DDR weder über direkte kommerzielle Kontakte noch über dritte Personen oder Länder indirekte Beziehungen zur Republik Südafrika" unterhalte. ${ }^{68}$

Trotz der Konkurrenzsituation der beiden Geheimdienste ${ }^{69}$ dürften sie sich in solch wichtigen Dingen kaum angelogen haben. Es bleibt also als gesicherte Erkenntnis $z u$ konstatieren, dass die DDR-Verantwortlichen nichts über eine eventuelle Weiterverwendung der Exportgüter aus ihrem Lande wussten oder wissen wollten und dass die südafrikanische Seite äußerst konspirativ an die Waren ihres Begehrens gelangte.

Solch ein Nichtwissen setzt allerdings voraus, dass es einen Handel über Drittstaaten tatsächlich gegeben hat, worüber allerdings bislang keinerlei handfeste Beweise vorliegen. Und anders herum: Die Südafrikaner hätten, wenn es denn Handelskontakt zur DDR gegeben hätte, ihre zum Export bestimmten Rohstoffe zunächst an „unbelastete“ Zwischenhändler verkaufen müssen, von denen die DDR die Waren hätte einkaufen können. Diese Transaktionen hätten in den ostdeutschen nunmehr zugänglichen Archiven sicherlich Spuren hinterlassen, die indes trotz größter Anstrengungen nicht gefunden werden konnten.

Aufschlussreich in diesem Zusammenhang ist die Meinung der US-amerikanischen Politikwissenschaftlerin Brigitte $H$. Schulz, die zu den dargelegten Fakten folgenden Standpunkt vertritt: „Since the GDR is involved in heavy trading with West Germany via so-called inter-German trade, it is difficult to say to what extent East German products reach the South African market or vice versa. That some of this trade does take place should be assumed; however, the GDR is not directly involved in this trade per se. This point was brought up by the author when interviewing various academics while conducting research in the GDR during 1983/84 and summer of 1985. The answer always was that what the West Germans do with East German products is no longer of concern to the GDR, indicating a

67 Vgl. BStU: MfS-Zentralarchiv, Arbeitsbereich Mittig, Nr. 140, Bl.480: Brief vom 17.6. 1983.

68 Vgl. ebenda: Brief des stellvertretenden MfS-Ministers, Generalleutnant Rudi Mittig, an Leiter der Hauptverwaltung Aufklärung, Generaloberst Markus Wolf, vom 1.8. 1983, Bl. 477.

6:) Vgl. Andreas Kabus, Auftrag Windrose. Der militärische Geheimdienst der DDR, Berlin 1993; Walter Richter, Der Militärische Nachrichtendienst der Nationalen Volksarmee und seine Kontrolle durch das Ministerium für Staatssicherheit. Die Geschichte eines deutschen Geheimdienstes, Frankfurt a. M. u.a. ${ }^{2004}$; Klaus Behling, Der Nachrichtendienst der NVA. Geschichte, Aktionen und Personen, Berlin 2005 . 
capacity for political cynicism that comes close to matching that of the FRG and its allies in the West. “70

Auch Dokumente aus dem Archiv des Ministry of Foreign Affairs of South Africa (Pretoria) aus jenen Jahren deuten darauf hin, dass es von Seiten der DDR keine bewussten Kontakte zu Handelsvertretern Südafrikas gegeben hat. Sie belegen indes für die Zeit ab den späten 1970er Jahren ein deutliches Interesse der Südafrikaner, mit der DDR wirtschaftliche Beziehungen herzustellen. So lassen sich praktische Bestrebungen von Seiten der südafrikanischen Regierung feststellen, sich eingehend über die potentiellen Partner aus dem anderen Teil Deutschlands ${ }^{71}$ zu informieren, d.h. die Namen von Politikern, deren Kompetenzbereiche und ähnliche Angaben zu eruieren. ${ }^{72}$

In einem als "geheim“ eingestuften Schreiben übermittelte dann auch die „Security Branch" der South African Police dem Verteidigungsministerium sowie dem Außenministerium in Pretoria eine Übersicht über die „Personelle Besetzung des Staats- und Parteienapparates der DDR“ vom August $1978 .{ }^{73}$ Am 12. November 1980 kursierte im südafrikanischen Außenministerium eine „Background Information on GDR“, die die Kenntnis einer ausgewählten Leserschaft über den anderen deutschen Staat erweitern sollte ${ }^{74}$ - auch dies ein indirekter Beleg dafür, dass es keine aktuellen offiziellen Kontakte gab.

Anfang der 1980er Jahre war die DDR für die südafrikanische Regierung noch immer weitgehend Terra incognita ${ }^{75}$, was sehr verwundert, mussten doch die Offiziellen der Apartheidregierung und der -polizei bzw. der südafrikanischen Geheimdienste wissen, dass die DDR ihre schlimmsten Gegner, nämlich Kämpfer von Umkhonte We Sizwe, dem militärischen Arm des ANC, auf ihrem Territorium ausbildete ${ }^{76}$. Diese Tatsache war in Pretoria durchaus bekannt: Nicht von ungefähr interessierte man sich im südafrikanischen Außen-

\footnotetext{
${ }^{70}$ Brigitte H. Schulz, The Two German States and Apartheid, in: Journal für Entwicklungspolitik, Nr. 4, 1988, S. 12, Anm. 39.

${ }^{71}$ Und dies, obwohl die Kontakte zur Bundesrepublik zu jener Zeit bekanntlich noch recht gut verliefen. Vgl. Claudius Wenzel, Südafrika-Politik der Bundesrepublik Deutschland 1982-1992. Politik gegen Apartheid?, Wiesbaden 1994; Peter Meyns, Cooperation without Change. The Foreign Policy of the Federal Republic of Germany in Southern Africa, Bonn 1987; Rainer Falk, Die heimliche Kolonialmacht. Bundesrepublik und Dritte Welt, Köln 1985; Reinhard Rode, Die Südafrikapolitik der Bundesrepublik Deutschland 1968-1972, München/Mainz. 1975; ders., Bonn und Pretoria. Lerndefizite und Lernerfolge in der Südafrika-Politik der Bundesrepublik, in: Helmut Bley/Rainer Tezlaff (Hrsg.), Afrika und Bonn. Versäumnisse und Zwänge deutscher Afrika-Politik, Reinbek bei Hamburg 1978, S.88ff.; Tilman Dedering, Ostpolitik and the Relations between West Germany and South Africa, in: Carole Fink/Bernd Schaefer (Hrsg.), Ostpolitik, 1969-1974. European and Global Responses, Cambridge 2009, S. 206ff. Die Kontakte der Bundesrepublik жum Apartheidstaat wurden von DDR-Seite nach wie vor kritisch beobachtet und kommentiert, so beispielsweise in: Memorandum über die Zusammenarbeit der BRD mit Südafrika auf militärischem und atomarem Gebiet, Dresden 1964; Das Bündnis Bonn-Pretoria, Dresden 1967; beides hrsg. vom Afro-Asiatischen Solidaritätskomitee der Deutschen Demokratischen Republik. Zu der Entlarvungskampagne vgl. ebenfalls BStU: MfS-Zentralarchiv, ZAIG, Nr. 10890.

${ }^{72}$ Ein vorhergehender Versuch des südafrikanischen Botschafters in Bonn, sein Außenministerium mit den politischen, ökonomischen, demographischen und sonstigen in der DDR vorherrschenden Verhältnissen vertraut zu machen (Schreiben vom 23.2.1971), scheint noch auf keinen großen Widerhall gestoßen zu sein. Vgl. Archive of the Department of Foreign Affairs, RSA, Pretoria: 1/154/1, Vol. 12 (o. P.).

73 Ebenda, Vol. 18, Bl. 125.

74 Vgl. ebenda, Vol. 22 (o. P.)

75 Vgl. Ian Greig, East Germany's Drive for Influence in Africa, in: ISSUP [Institute for Strategic Studies, L'niversity of Pretoria] Bulletin, Strategiese Oorsig, 6/1985, S. 19ff.

76 Vgl. Howard Barrell, MK. The ANC's Armed Struggle, London 1990, S. 43.
} 
ministerium für die Anti-Terror-Gesetze der Bundesrepublik zur Zeit der Aktivitäten der RAF, denn die ANC-Kämpfer wurden von den Apartheidstrategen in deren ideologischer und politischer Nähe gesehen. ${ }^{77}$ Damit lagen die Diplomaten, Politiker und Sicherheitsexperten des Apartheidstaates in ihren Auffassungen nicht so weit entfernt von der häufig geäußerten Meinung, in den im Süden Afrikas existierenden Befreiungsorganisationen ANC und SWAPO sowie in der SACP „terroristische Banden nach dem Vorbild der westdeutschen RAF“ zu erblicken. ${ }^{78}$ Insbesondere Franz Josef Strauß und seine CSU meinten in den südafrikanischen Befreiungsorganisationen „pro-kommunistische“ und „terroristische" Gruppen ausgemacht zu haben. ${ }^{79}$

\section{Die 1980er Jahre: Vehemente Versuche zur Aufnahme von Handelskontakten}

Zu Beginn der 1980er Jahre begannen südafrikanische Regierungsvertreter, sich aktiv um Handelsbeziehungen zur DDR und um Zusammentreffen mit deren Vertretern zu bemühen. ${ }^{80}$ Offensichtlich hatte das südafrikanische Außenministerium noch Ende der 1970er Jahre vermutlich nichts von Handelsbeziehungen von Geschäftsleuten der RSA zur DDR gewusst bzw. solche nicht befördert. Überhaupt fällt auf, wie wenig Interesse im „Sekretaris van Buitelandse Sake“, so die Afrikaans-Bezeichnung für das südafrikanische Außenministerium, an der DDR zu jener Zeit vorhanden war. In einem Brief vom 20. Dezember 1978 wies der südafrikanische Botschafter in Brüssel nämlich sein Ministerium darauf hin, dass die DDR an einem chronischen Mangel an Konsumgütern leide. Konstatiert wurde dies anhand der augenscheinlich festgestellten Zunahme von entsprechenden Annoncen zum An- und Verkauf von Konsumprodukten in den einschlägigen DDR-Zeitungen. ${ }^{81}$ Ohne Zweifel wurde diese Information ans Ministerium in Pretoria geliefert, weil die Brüsseler Diplomaten aus Südafrika somit Schützenhilfe bei der Anbahnung von Handelskontakten zwischen beiden Ländern leisten wollten.

Materialien des MfS belegen dann besonders für das Jahr 1984 intensivere Versuche südafrikanischer Handelsvertreter, Kontakt zu DDR-Außenhändlern herzustellen. Dies geschah beispielsweise über kleinere österreichische Handelsgesellschaften, die vermutlich zunächst herausfinden sollten, inwieweit DDR-Außenhandelsvertreter für Zusammentreffen mit südafrikanischen Regierungsbevollmächtigten überhaupt bereit seien. Diese Firmen agierten dabei offensichtlich im Auftrag des Handelsrates der RSA in Österreich und traten während der Leipziger Herbstmesse 1984 zum ersten Mal nachweislich in Erscheinung. Den Ausführungen der südafrikanischen Bevollmächtigten zufolge war der Grund der vorsichtigen Kontaktaufnahme der Tatsache geschuldet, dass der südafrikanische Prä-

\footnotetext{
77 Vgl. Archive Department of Foreign Affairs, RSA, Pretoria: 1/154/1, Vol. 17, passim.

78 Klaus Freiherr von der Ropp, Das südliche Afrika - Umbruch, Aufbruch, Zusammenbruch? Ansichten eines Dissidenten, in: Thomas Jäger/Gerhard Kümmel/Monika Lerch/Thomas Noetzel (Hrsg.), Sicherheit und Freiheit. Außenpolitische, innenpolitische und ideengeschichtliche Perspektiven. Festschrift für Wilfried von Bredow, Baden-Baden 2003, S.365.

${ }^{79}$ Entspannung muß unbrechbar sein. Ein internes Papier von CDU und CSU für die noch ausstehenden Koalitionsgespräche über die künftige Orientierung der deutschen Afrikapolitik, in: Frankfurter Rundschau vom 30.3.1983.

${ }^{80}$ Vgl. BStU: MfS-Zentralarchiv, HA XVIII, Nr. 7466 (o. P.): Verhalten der Delegation Südafrikas auf der Tagung der internationalen Kommission für die Südostatlantik-Fischerei (Namibia) in Spanien im Dezember 1981.

${ }^{81}$ Vgl. Archive Department of Foreign Affairs, RSA, Pretoria: 1/154/1, Vol. 18, Bl.9.
} 
sident Pieter Willem Botha mit den ökonomischen und politischen Ergebnissen seiner gerade stattgefundenen Westeuropareise nicht zufrieden gewesen sei und er nunmehr versuchen wolle, den „sozialistischen Markt“ zu erschließen.

In der Tat war der südafrikanische Präsident Pieter Willem Botha auf seiner Europatour vor allem in der Bundesrepublik Deutschland abweisend behandelt worden. Es war Anfang Juni 1984 das erste Mal gewesen, dass ein südafrikanischer Regierungschef ihr einen offiziellen Besuch abgestattet hatte. Klaus Freiherr von der Ropp, einer der besten Kenner der deutsch-südafrikanischen Beziehungen sowie der bundesdeutschen Afrikapolitik insgesamt, beschreibt die Visite wie folgt: „Aus Rücksichtnahme auf die vielen deutschen und afrikanischen Kritiker dieses Besuches, insbesondere auf den entsprechenden Widerstand kirchlicher Kreise gegen den Empfang Bothas durch den Bundeskanzler, verlief der Empfang durch Helmut Kohl frostig. Die Südafrikaner empfanden ihn obendrein als demütigend. “82

Die südafrikanische Regierungsdelegation war vor allem deshalb konsterniert, weil demonstrativ die Sitzmöbel im Bundeskanzleramt, auf denen der Bundeskanzler und seine ausländischen Gäste für gewöhnlich Platz nahmen, kurze Zeit vor Ankunft des Gastes aus Pretoria herausgetragen worden waren. Anschließend hieß der Kanzler seinen Gast im Stehen und ohne Handschlag vor laufenden Kameras willkommen. ${ }^{83}$

Von der Leipziger Messe wurde vom MfS der SED-Parteiführung in Berlin berichtet, dass der südafrikanische Handelsrat in Österreich, der Generalbevollmächtigte einer Londoner Bank sowie der Inhaber einer südafrikanischen Handelsvertretung in Österreich in Gesprächen mit verdeckt für das MfS arbeitenden DDR-Handelsvertretern zum Ausdruck gebracht hätten, „dass sie nicht als Privatpersonen in Leipzig weilen, sondern im Auftrag der südafrikanischen Regierung zur Messe gekommen seien“. Ihr Ziel sei es, Kontakte zu Wirtschaftseinrichtungen der DDR herzustellen, um branchenunabhängig die gegenseitigen Interessen auf wirtschaftlichem Gebiet abzuklären. Die Südafrikaner hatten etwa Mitte der 1980er Jahre umso mehr ein Interesse an Geschäftsbeziehungen zur DDR, weil man im Außenministerium in Pretoria davon ausging, „dass eine Zusammenarbeit zwischen einem afrikanischen Staat und der DDR Bonn nun nicht mehr stören wird“" 84

Trotz der für die DDR-Wirtschaft äußerst verlockend erscheinenden Angebote der südafrikanischen Vertreter auf der Leipziger Messe ging die Regierung in Ostberlin bzw. ihre nachgeordneten Behörden aufgrund der internationalen Bestimmungen zum Boykott des Apartheidregimes nicht darauf ein. Die geschilderten Kontaktversuche verliefen im Sand.

Erst zu den Leipziger Messen in den Jahren 1988 und 1989 sind dann wieder verstärkt verdeckt eingereiste angebliche südafrikanische Außenhändler dem MfS bekannt geworden, die insbesondere Interesse an Erzeugnissen aus dem Hochtechnologiebereich und der Nachrichtenelektronik aus DDR-Produktion bekundeten, namentlich an Erzeugnissen aus den Kombinaten Robotron und Carl Zeiss Jena. ${ }^{85}$ Für den Fall des Zustandekommens direkter oder „abgedeckter“ Lieferungen boten die Vertreter des immer weiter in die internationale Isolierung geratenen Apartheidregimes im Gegenzug Rohstofflieferungen in die DDR und gar Unterstützung beim Bezug von Waren mit Embargo-Charakter an. ${ }^{86}$

82 Klaus Freiherr von der Ropp, Südafrikas dorniger Weg auf der Suche nach Frieden, Aufsätze 19751995, Baden-Baden 1996, S. 127.

${ }^{83}$ Vgl. ebenda, Anm. 7, vgl. auch von der Ropp, Das südliche Afrika, S. 371.

${ }^{84}$ Archive Department of Foreign Affairs, RSA, Pretoria: 1/154/1, Vol. 12 (o. P.): „... dat samewerking van 'n Afrika-staat met die DDR nie meer vir hom Bonn se gramskap op die hals sal haal nie".

*5 Vgl. BStU: MfS-Zentralarchiv, HA XVIII, Nr.9062: Information Nr. 153/89, 3.5. 1989.

sti Vgl. ebenda, Bl. 3 . 
Es ist festzustellen, dass in der zweiten Hälfte der 1980er Jahre sich zusehends die Bestrebungen von Geschäftskreisen der RSA zur Herstellung kommerzieller Kontakte zur DDR verstärkten und deren Angebote differenzierter wurden. Das rief selbstverständlich das Interesse des MfS hervor. In einer recht umfangreichen und ausführlichen Information für einen Kreis hochrangiger Politiker der DDR sowie für Geheimdienstmitarbeiter wurde eingeschätzt: „Im Rahmen der Sicherung von NSW-Außenwirtschaftsbeziehungen ${ }^{87}$ des Industriebereiches Elektrotechnik/Elektronik sind Hinweise bedeutsam, die auf wachsendes Interesse von Geschäftskreisen der Republik Südafrika am Bezug von Erzeugnissen des Industriebereiches deuten. Es handelt sich dabei um Erzeugnisse, die dem Hochtechnologiebereich zuzuordnen sind aus den Kombinaten Robotron, Carl Zeiss Jena und Nachrichtenelektronik. Bereits seit längerem suchen Vertreter von Handelsfirmen der Republik Südafrika, abgedeckt über Firmen in Simbabwe und in anderen Ländern des südafrikanischen Raumes, kommerziellen Kontakt zu DDR-Auslandskadern; des weiteren sind abgedeckte Einreisen südafrikanischer Vertreter u.a. zu den Leipziger Messen 1988/89 bekannt. Es kann somit eingeschätzt werden, dass südafrikanische Geschäftskreise in erster Linie bereits bestehende Geschäftsbeziehungen von Handelsfirmen in Ländern des südafrikanischen Raumes mit den o.g. Erzeugnissen repräsentierenden AHB [Außenhandelsbetrieb - U. v. d. H.] für ihre kommerziellen Interessen nutzen. "88 Es wurde in dem zitierten Dokument weiterhin mitgeteilt, dass die „im Auftrag der südafrikanischen Regierung“ agierenden Handelsvertreter während der Leipziger Frühjahrsmesse 1989 Bezugsmöglichkeiten für IBM-kompatible Rechentechnik aus dem Kombinat Robotron abgeklärt hätten. Ihr spezielles Interesse galt dabei dem Rechner K 1840 (32-bit-Rechner) sowie Software für Konstruktions- und Technologiearbeitsplätze. Es erschien den Mitarbeitern des MfS bedeutsam zu sein, dass der in Gesprächen angedeutete Einsatzzweck von Robotron-Rechnern in sicherheitsrelevanten und militärischen Bereichen, so unter anderem im Pass- und Meldewesen sowie zur Luftraum- und Seeüberwachung, liegen solle.

Das MfS vermerkte mit Interesse, dass die die Leipziger Messe besuchenden südafrikanischen Unterhändler einen Informationsbedarf zur DDR, aber auch zum gesamten „Ostblock“ hatten. In der trockenen MfS-Berichterstattung liest es sich wie folgt: „Bemerkenswert ist auch der Umstand, dass die südafrikanischen Vertreter - die sich in kommerziellen Gesprächen mit DDR-Verhandlungskadern konsequent jeglicher politischer Meinungsäußerungen enthielten - im konspirativen Umgang mit Zielpersonen Informationsinteressen erkennen ließen, mit eindeutig politischem Charakter. So forderten sie u.a. Informationen zum Umgestaltungsprozess in der UdSSR, zur Perspektive der Zusammenarbeit UdSSR - DDR, zu Erwartungen der DDR-Bevölkerung zum XII. Parteitag der SED, zur Rolle der Jugend in der DDR.“ Zum Schluss der „Information“ kommt das MfS zu der kaum noch erstaunlichen Erkenntnis, dass „angesichts der außerordentlichen Brisanz des Problemkreises ein geheimdienstlicher Hintergrund der [...] kommerziellen Aktivitäten nicht auszuschließen ist“.

In der Tat gab es noch im letzten Jahr der Existenz der DDR weitere Versuche des Apartheidregimes mit der DDR Handelsverbindungen und vielleicht auch politische Kontakte aufzunehmen. ${ }^{89}$ Dies führte dann zu verstärkten Aktivitäten des MfS ${ }^{90}$ Zum Teil knüpften

\footnotetext{
87 NSW = Nichtsozialistisches Weltsystem.

${ }^{88}$ BStU: MfS-Zentralarchiv, HA XVIII, Nr.4526, Bl. 1 ff. Die folgenden, nicht näher ausgewiesenen Zitate stammen aus diesem Dokument.

89 Vgl. BStU: MfS-Zentralarchiv, HA II, Nr. 28725, Bl.54ff.

90 Vgl. ebenda, $\mathrm{Bl} .44$
} 
die südafrikanischen Unterhändler an Aktivitäten an, mit denen sie oder ihre Kollegen schon Jahre zuvor erfolglos versucht hatten, Kontakte zu DDR-Außenhändlern, vor allem zu denen aus der elektronischen Branche, aufzunehmen. ${ }^{91}$

Der DDR war allerdings nicht so sehr an Handelsbeziehungen mit dem Apartheidregime gelegen, als vielmehr an guten Wirtschaftskontakten zu einem Südafrika nach der Apartheid.

So schätzte das MfS schon 1987/88 in einer Studie mit dem Titel „Zur politischen Lage in der Südafrikanischen Republik (RSA) [sic!]“ ein: „Es ist davon auszugehen, dass der südafrikanische Markt nach Beseitigung des Apartheidsystems die gleichen Bedingungen und Voraussetzungen wie andere kapitalistische Märkte bieten wird. Südafrika wird vorrangig ein aufnahmefähiger und expandierender Markt für hochentwickelte Erzeugnisse der metallverarbeitenden Industrie sowie wissenschaftlich-technische Leistungen sein und internationale Kooperationsbeziehungen in den wichtigsten Volkswirtschaftsbereichen auf hohem Niveau entwickeln können.“

Das MfS kam zu dem Schluss, dass in Übereinstimmung mit den Beschlüssen der UNO und ausgehend von ihrer prinzipiellen Haltung zum Apartheidsystem die DDR auch weiterhin keine Beziehungen, darunter Wirtschafts- und Handelsbeziehungen, zum Apartheidregime in Südafrika unterhielt. Versuche südafrikanischer Firmen oder anderer Vertreter Südafrikas zur Geschäftsanbahnung sollten prinzipiell zurückgewiesen werden.

Um die Aufnahme von Beziehungen der DDR, darunter ökonomischer und wissenschaftlich-technischer Beziehungen, zu einem demokratischen und nichtrassistischen sowie international anerkannten südafrikanischen Staat vorzubereiten, sei, so das MfS, die Analyse der politischen und wirtschaftlichen Entwicklung in Südafrika kontinuierlich fortzusetzen und zu vertiefen, und es seien in Abstimmung mit dem ANC die Kontakte mit politischen Kräften der breiten Anti-Apartheid-Bewegung innerhalb Südafrikas, darunter zu Vertretern der Wirtschaft, zu entwickeln und auszubauen. ${ }^{92}$

Ähnliche strategische Überlegungen waren bereits Ende der 1970er Jahre in Hinblick auf eine vermutete bevorstehende Unabhängigkeit Namibias zu Papier gebracht worden. ${ }^{93}$

Jedoch war es die DDR nicht allein, die sich auf die zukünftigen Beziehungen zur Republik Südafrika nach Beseitigung der Apartheid vorbereitete, sondern auch andere Staaten des damaligen sozialistischen lagers. Nicht nur die DDR, auch die Sowjetunion setzte hohe Erwartungen in den zukünftigen Handel mit Südafrika. Aus diesem Grunde nahm die UdSSR schon recht frühzeitig Kontakte zu Wirtschaftskreisen im Süden Afrikas auf. ${ }^{94}$ Wohl alle Staaten des sozialistischen Lagers erhofften sich nach einem politischen Wandel in der RSA gute Startbedingungen und wohl auch eine Kompensation der bisher durch die Boykottmaßnahmen entstandenen wirtschaftlichen Verluste.

\footnotetext{
"11 Vgl. hierzu ausführlicher Ulrich van der Heyden, Zwischen Solidarität und Wirtschaftsinteressen. Die "geheimen" Beziehungen der DDR zum südafrikanischen Apartheidregime, Münster 2005.

${ }_{92}$ Vgl. BStU: MfS-Zentralarchiv, HA XVTII, Nr.7956, Bl.7: Zur politischen Lage in der Südafrikanischen Republik (RSA).

${ }_{93}$ Vgl. BStL: MfS-7entralarchis, SdM, Nir. 1641, Bl.22ff.

94 Vgl. Winrich Kühne, Gibt es eine neue sowjetische Südafrikapolitik? Zur Kontroverse der beiden stellvertretenden Direktoren des Moskauer Afrika-Instituts, Ebenhausen 1988. Vgl. auch ders., Gorbatschow und das südliche Afrika. Zum Wandel im afrikapolitischen Denken der Sowjetunion, in: Christine Lienemann-Perrin/Wolfgang Lienemamn (Hrsg.), Politische Legitimität in Südafrika, Heidelberg 1988 , S. $182 \mathrm{ff}$.
} 
Abstimmungen innerhalb des damaligen sozialistischen Lagers über die zukünftigen Beziehungen zu einem von der Apartheid befreiten Südafrika gab es nicht. Überhaupt ist nach dem Studium der einschlägigen Akten auffallend, wie autonom die einzelnen Staaten des Warschauer Paktes agierten. In Bezug auf die Abstimmung ihrer Afrikapolitik mit der Sowjetunion kann nicht, wie in so vielen anderen Bereichen, von einer Abhängigkeit der DDR vom "großen Bruder" gesprochen werden, sondern eher von einer ,Juniorpartnerschaft" ${ }^{\text {“95 }}$ Die UdSSR verlor insbesondere seit Mitte der 1980er Jahre allerdings ebenfalls das Interesse an einer strikten Anti-Apartheid-Politik. Sowohl aufgrund fehlender Ressourcen als auch aufgrund politisch-ideologischer Desillusionierungen seit dem Machtantritt von Gorbačev war die Sowjetunion weder an einem breit angelegten Engagement noch an einem Konflikt mit den USA in der südafrikanischen Region interessiert ${ }^{96}$, so dass in der zweiten Hälfte der 1980er Jahre von einem „neuen Realismus“ in der sowjetischen Afrikapolitik gesprochen wurde ${ }^{97}$.

Nicht zuletzt auf Grundlage der Erkenntnis von Afrika-Spezialisten aus dem Moskauer Außenministerium waren die Politiker im Kreml - im Gegensatz zu ihrer noch vor wenigen Jahren betriebenen Afrikapolitik ${ }^{98}$ - zu der Ansicht gelangt ${ }^{99}$, dass sich die ökonomischen und militärischen Interessen der USA im südlichen Afrika in einem überschaubaren Rahmen hielten ${ }^{100}$, so dass sie wohl aus dieser Einschätzung heraus kein sonderliches Interesse daran hatten, ihre Verbündeten, besonders die DDR, in dieser Beziehung zu gängeln.

Im Unterschied zu den anderen Staaten des sozialistischen Lagers - vielleicht mit Ausnahme der Sowjetunion - erhoffte sich die DDR günstigere Ausgangsbedingungen bei der Gestaltung der zukünftigen Beziehungen mit einem freien Südafrika. Man stützte sich bei diesen Hoffungen nicht zuletzt auf die umfangreiche Hilfe, die man den Anhängern der ANC, der Kommunistischen Partei und anderen Südafrikanern hatte zuteilwerden lassen. Dass diese Erwartungen nicht unbegründet waren, merken deutsche Besucher des Öfteren im Land am Kap, wenn sie noch nach fast 20 Jahren deutscher Einheit nach der geographischen Herkunft gefragt werden.

95 Hans-Georg Schleicher, Juniorpartner der Sowjetunion. Die DDR im südlichen Afrika, in: Michael Behrens/Robert von Rimscha (Hrsg.), Südafrika nach der Apartheid. Aspekte des politischen, sozioökonomischen und kulturellen Wandels in der Ära de Klerk, Baden-Baden 1996, S. 65ff.

96 Vgl. Winrich Kühne, Die Sowjetunion und die Gefährdung westlicher Interessen in Afrika. Mythos und Realität, in: Rudolf Hamann (Hrsg.), Die „Süddimension“ des Ost-West-Konfliktes, Baden-Baden 1986, S. $105 \mathrm{ff}$.

97 Vgl. ders., „Neuer Realismus“ in Moskaus Afrika-Politik?, in: Aus Politik und Zeitgeschichte, Bd. 7-8/1988, S.31 ff.

98 Vgl. hierzug Konrad Melchers, Die sowjetische Afrikapolitik von Chruschtschow bis Breschnew, Berlin (W) 1980.

99 Vgl. Claudius Wenzel, Die Südafrikapolitik der USA in der Ära Reagan. Konstruktives oder destruktives Engagement?, Hamburg 1990, S. 42.

${ }^{10}$ Vgl. William J. Foltz, U. S. National Interests in Africa, in: Prasser Gifford (Hrsg.), The National Interest of the United States in Foreign Policy, Washington, D. C. 1981, S.93ff.; ders., United States Policy towards South Africa. Is One Possible?, in: Gerald J. Bender/James S. Coleman/Richard L. Sklar (Hrsg.), African Crisis Areas and U. S. Foreign Policy, Berkeley/Los Angeles/London 1985, S. 32ff.; Helen Kitchen, Africa. Year of Ironies, in: Foreign Affairs, Vol.64, No.3, 1986, S.563f. 